\title{
Glomerular Proteinuria Induces Heme Oxygenase-1 Gene Expression within Renal Epithelial Cells
}

\author{
MASAKI SHIMIZU, KAZUHIDE OHTA, YONGHONG YANG, AKIKO NAKAI, TOMOKO TOMA, \\ YUTAKA SAIKAWA, YOSHIHITO KASAHARA, AKIHIRO YACHIE, HITOSHI YOKOYAMA, \\ HIDETOSHI SEKI, AND SHOICHI KOIZUMI \\ Department of Pediatrics [M.S., K.O., Y.Y., A.N., T.T., Y.S., Y.K., S.K.], Graduate School of Medical \\ Science, Kanazawa University, Division of Blood Purification, Kanazawa University Hospital [H.Y.], \\ Department of Laboratory Sciences [A.Y.] and Department of Nursing [H.S.], School of Health Sciences, \\ Faculty of Medicine, Kanazawa University, Kanazawa, Ishikawa 920-8641, Japan
}

\begin{abstract}
ABS
To clarify the patterns of heme oxygenase-1 (HO-1) produc-
tion within the human kidney, we examined HO-1 mRNA ex-
pression in various renal diseases and compared the patterns with
those of HO-1 protein expression and these data with the clinical
features. The degrees of hematuria and proteinuria and the levels
of urinary N-acetyl- $\beta$-D-glucosaminidase (NAG), $\beta_{2}$-micro-
globulin ( $\beta_{2}$-mg), and creatinine were determined. In situ hy-
bridization and immunohistochemical studies were performed to
evaluate HO-1 expression. HO-1 mRNA was detectable within
tubular, glomerular, and Bowman's epithelial cells and infiltrat-
ing macrophages. Within the proximal tubuli, there was a corre-
lation between expression of HO-1 protein and mRNA, but the
intensity of HO- 1 mRNA expression was much less than ex-
pected from the levels of protein. In contrast, both HO-1 protein
and mRNA were expressed at significant levels within distal
tubuli. Furthermore, there was no correlation with both expres-
sions within distal tubuli. HO-1 mRNA expression within tubu-
lar, glomerular, and Bowman's epithelial cells tended to be more
intense with greater degrees of proteinuria. However, there was
\end{abstract}
Heme oxygenases (HOs) are rate-limiting enzymes that catalyze the conversion of heme to biliverdin, carbon monoxide, and iron (1-3). Biliverdin is subsequently converted to bilirubin by biliverdin reductase and has potent antioxidant and anticomplement effects $(4,5)$. Carbon monoxide acts as a potent vasodilator and inhibitor of platelet aggregation $(6,7)$. Furthermore, degradation of heme by HOs leads to the induc-

Received July 14, 2004; accepted March 5, 2005.

Correspondence: Kazuhide Ohta, M.D., Ph.D. Department of Pediatrics, Graduate School of Medical Science, Kanazawa University, 13-1 Takaramachi, Kanazawa, Ishikawa 920-8641, Japan; e-mail: kohta@ped.m.kanazawa-u.ac.jp.

Supported by a grant-in-aid for Scientific Research from the Japan Foundation of Cardiovascular Research; by a grant-in-aid for Scientific Research from the Ministry of Education, Science and Culture of Japan; and by a grant from the Ministry of Health and Welfare of Japan.

DOI: 10.1203/01.PDR.0000180557.68222.5A little correlation between the intensity of HO-1 mRNA expression and the degree of hematuria, NAG, and $\beta_{2}-\mathrm{mg}$. HO-1 plays important roles in maintaining renal functions by protecting renal epithelial cells from glomerular proteinuria, which can become a cause of oxidative stress. Furthermore, from the different expression pattern of HO-1 gene between within the proximal tubuli and within the distal tubuli, renal expression of HO- 1 is regulated in a segment-specific manner, with HO-1 thereby playing distinct roles in different segments of the nephron to maintain renal functions. (Pediatr Res 58: 666-671, 2005)

DIG, digoxigenin

\section{Abbreviations}

HO, heme oxygenase

MCNS, minimal-change nephrotic syndrome

Mes-PGN, mesangial proliferative glomerulonephritis

NAG, $\mathrm{N}$-acetyl- $\beta$-D-glucosaminidase

THP, Tamm-Horsfall protein

$\boldsymbol{\beta}_{\mathbf{2}}$-mg, $\beta_{2}$-microglobulin tion of ferritin synthesis, which then may sequester free iron and prevent it from participating in subsequent oxidative injury $(8-10)$. Therefore, HOs have antioxidant capacity and act as potent anti-inflammatory proteins whenever oxidative injury takes place. They consist of three different isoforms. One is HO-1, which is an inducible form of the enzyme. The second is HO-2, which is a constitutive form of the enzyme expressed within the brain and testis. Recently, the third form, HO-3, has been reported as well (11).

We previously reported that HO-1 immunostaining in human renal tissues was observed only within tubular epithelial cells and infiltrating macrophages in all renal diseases (12). In contrast, it was not detected within intrinsic glomerular cells, such as glomerular epithelial cells, glomerular endothelial cells, or mesangial cells. Many studies in various animal 
models also suggested that HO-1 protein production in renal tissues was restricted to tubular epithelial cells (13-20). However, in vitro studies have indicated that HO-1 is induced not only within tubular epithelial cells but also within glomerular epithelial cells, mesangial cells, vascular endothelial cells, and various other cells (21-24). To clarify these differences, we compared the HO- 1 production induced in response to oxidative stress between within primary cultured human mesangial cells and within human proximal tubular epithelial cells. These two different cells showed distinct patterns of HO-1 production in terms of kinetics and dose response (25). In this study, we examined HO-1 mRNA expression in vivo in various renal diseases by in situ hybridization and compared it with HO-1 protein expression as related to various clinical features.

\section{METHODS}

Patients. A total of 94 patients with various renal diseases were enrolled in this study. One additional patient with HO-1 deficiency served as a HO-1 negative control. Diagnoses were confirmed by histopathologic evaluation of renal biopsy specimens, comprising light microscopy, electron microscopy, and immunofluorescence staining. Included among these were nine cases of minimal-change nephrotic syndrome (MCNS), 63 cases of mesangial proliferative glomerulonephritis (Mes-PGN; IgA nephropathy, purpura nephritis, and non-IgA nephropathy), nine cases of tubulointerstitial nephritis, three cases of acute tubular necrosis, three cases of focal segmental glomerulosclerosis, four cases of systemic lupus erythematosus, and three cases of membranoproliferative glomerulonephritis. The materials for histopathologic examinations were obtained from these patients by renal biopsy. Only four cases showed elevated serum creatinine above the age-matched normal range in acute phase. In all of the four cases, their serum creatinine normalized in convalescence. All of the patients with MCNS were frequent relapsers or steroid dependent, and a renal biopsy was performed to distinguish it from other forms of renal diseases or to exclude the possibility of cyclosporin A nephropathy. Only one of the patients with MCNS was receiving cyclosporin $\mathrm{A}$, whereas none of the other MCNS patients was receiving it or any other immunosuppressive agents. Proteinuria was absent in four patients with MCNS, and heavy proteinuria was present in five other patients at the time of renal biopsy. We enrolled four MCNS patients without proteinuria at the time of biopsy as normal control subjects. They all were free of any medication. The duration of these diseases was variable, ranging from several days to more than several years. The characteristics of these cases are shown in Table 1. This study was approved by the Institutional Review Board at Kanazawa University Hospital, and all specimens were used after the receipt of informed consent.

Urinalysis. Routine urinalysis and biochemical study were performed with fresh urine specimens, and the residual samples were stored at $-80^{\circ} \mathrm{C}$ for future analysis. Quantitative measurement of urinary protein concentrations was not available for all of the enrolled cases. For this reason, the levels of hematuria and proteinuria were evaluated from the data with dipsticks. Microscopic hematuria was graded as $(-),( \pm),(1+),(2+)$, and $(3+)$. Proteinuria was graded as (-), absent; ( \pm$), 10 \mathrm{mg} / \mathrm{dL} ;(1+), 30 \mathrm{mg} / \mathrm{dL} ;(2+), 100 \mathrm{mg} / \mathrm{dL}$;

Table 1. Characteristics of the enrolled patients

\begin{tabular}{lcccc}
\hline & $\begin{array}{c}\text { Number of } \\
\text { patients }\end{array}$ & Sex & $\begin{array}{c}\text { Mean age } \\
\text { years }\end{array}$ & $\begin{array}{c}\text { Patients with } \\
\text { elevated serum } \\
\text { creatinine N }\end{array}$ \\
\hline MCNS & 9 & $7 / 2$ & $6.9 \pm 5.9$ & $0 / 9$ \\
Mes-PGN & 63 & $31 / 32$ & $10.3 \pm 4.4$ & $1 / 63$ \\
$\quad$ IgA nephropathy & 39 & $20 / 19$ & $11.1 \pm 4.2$ & $1 / 39$ \\
$\quad$ Purpura nephritis & 21 & $11 / 10$ & $9.0 \pm 4.7$ & $0 / 21$ \\
$\quad$ Non-IgA nephropathy & 3 & $0 / 3$ & $10.0 \pm 4.4$ & $0 / 3$ \\
TIN & 9 & $2 / 7$ & $10.2 \pm 5.4$ & $2 / 9$ \\
ATN & 3 & $2 / 1$ & $12.3 \pm 2.3$ & $1 / 3$ \\
FSGS & 3 & $2 / 1$ & $6.0 \pm 3.6$ & $0 / 3$ \\
SLE & 4 & $1 / 3$ & $12.3 \pm 2.2$ & $0 / 4$ \\
MPGN & 3 & $0 / 3$ & $13.3 \pm 4.2$ & $0 / 3$ \\
HO-1 deficiency & 1 & $1 / 0$ & - & $0 / 1$ \\
Total & 95 & $46 / 49$ & $10.2 \pm 4.6$ & $4 / 95$ \\
\hline
\end{tabular}

$(3+), 300 \mathrm{mg} / \mathrm{dL}$; and $(4+), 1000 \mathrm{mg} / \mathrm{dL}$. Urinary NAG, $\beta_{2}$-mg, and creatinine levels were measured at our hospital laboratory.

Processing of renal tissue. Renal tissue samples for light microscopy examination, in situ hybridization, and immunohistochemical studies were fixed in $4 \%$ buffered paraformaldehyde, dehydrated with graded concentrations of ethanol and xylene, and then embedded in paraffin. For the routine immunofluorescence studies, 4- $\mu \mathrm{m}$-thick frozen sections were fixed in cold acetone and stored at $-20^{\circ} \mathrm{C}$ until examined. The specimens were investigated for deposits of $\operatorname{IgG}, \operatorname{IgA}, \mathrm{IgM}$, complement (C)1q, C3, C4, and fibrinogen using the direct immunofluorescence method. For routine electron microscopic examination, the samples were fixed in glutaraldehyde $[2 \% \mathrm{wt} / \mathrm{vol}$ in $0.1 \mathrm{M}$ cacodyl buffer ( $\mathrm{pH} 7.4)]$ for $2 \mathrm{~h}$ at $4^{\circ} \mathrm{C}$. The samples were washed with the buffer and postfixed in $1 \%$ osmium tetroxide in $0.1 \mathrm{M}$ cacodyl buffer for $1 \mathrm{~h}$. Then these samples were dehydrated and embedded in Epon resin. The sections $(100 \mathrm{~nm})$ were stained with uranyl acetate for $15 \mathrm{~min}$, followed by saturated lead citrate for $7 \mathrm{~min}$ before being examined under a transmission electron microscope.

In situ hybridization. The XhoI-XbaI fragment (986 bp) of pHHO1 was subcloned into pGEM vector (Promega, Madison, WI). The antisense and sense HO-1 RNAs were synthesized by SP6 and T7 RNA polymerase, respectively, and labeled with digoxigenin (DIG)-UTP using a Dig RNA Labeling Kit (Boehringer-Mannheim, Mannheim, Germany) according to the manufacturer's instructions. Before hybridization, $4-\mu \mathrm{m}$-thick sections were treated with proteinase $\mathrm{K}(20 \mu \mathrm{g} / \mathrm{mL})$ at $37^{\circ} \mathrm{C}$ for $30 \mathrm{~min}$ and postfixed with $4 \%$ paraformaldehyde in $0.1 \mathrm{M}$ phosphate buffer for $10 \mathrm{~min}$. Thereafter, the sections were treated with $0.2 \mathrm{~N} \mathrm{HCl}$ to inactivate internal alkaline phosphatase and acetylated with $0.25 \%$ acetic anhydrate in $0.1 \mathrm{M}$ triethanolamine ( $\mathrm{pH} 8.0$ ) for $10 \mathrm{~min}$. Prehybridization was carried out in 50\% formamide and 1× SSC at $50^{\circ} \mathrm{C}$ for $60 \mathrm{~min}$. Hybridization was carried out in hybridization buffer $(50 \%$ formamide, $1 \times \mathrm{SSC}, 10 \%$ dextran, $1 \times$ Denhardt's solution, and $1 \mu \mathrm{g} / \mathrm{mL}$ tRNA) at $42^{\circ} \mathrm{C}$ overnight. After a washing with $2 \times$ SSC and $1 \times$ SSC in each buffer that contained $50 \%$ formamide at $50^{\circ} \mathrm{C}$ for $30 \mathrm{~min}$, the sections were incubated with anti-DIG alkaline phosphatase-conjugated antibody. Excess antibody was washed away with PBS with $0.2 \%$ Tween 20, and the color substrate (nitro blue tetrazolium salt and 5-bromo-4-chloro-3-indolyl phosphate) was added, according to the manufacturer's protocol.

Immunohistochemistry. Immunostaining for $\mathrm{HO}-1$ or macrophage-specific antigen CD68 (KP-1) was performed with an anti-HO-1 rabbit antiserum (StressGen, Victoria, British Columbia, Canada) or an anti-CD68 MAb (Dako Co., Carpinteria, CA). Briefly, paraffin sections of the kidney were deparaffinized and rehydrated with descending ethanols. For HO-1 immunostaining, the sections were immersed in Target-Retrieval Solution (Dako) and heat treated in a microwave oven for $5 \mathrm{~min}$ at high power $(500 \mathrm{~W})$. Then the slides were immersed in hot Target-Retrieval Solution to cool for $30 \mathrm{~min}$ and rinsed in Tris buffer. For CD68 immunostaining, the slides were incubated with pronase $(0.5 \mathrm{mg} / \mathrm{mL}$; Dako) for $15 \mathrm{~min}$ at room temperature in a buffer solution that contained $0.05 \mathrm{M}$ Tris- $\mathrm{HCl}(\mathrm{pH} 7.2)$ and $0.1 \mathrm{M} \mathrm{NaCl}$. The slides were heat treated in the same manner as for the HO-1 staining. After blocking with normal goat serum, the sections were incubated with appropriate dilutions of each first antibody for $12 \mathrm{~h}$ at $4^{\circ} \mathrm{C}$. After the slides were washed in Tris buffer, tissue sections were incubated with EnVision polymer reagents (Dako), alkaline phosphatase, and goat anti-rabbit/mouse IgG-conjugated dextran polymer for $30 \mathrm{~min}$ at room temperature. Alkaline phosphatase activity was visualized using Fast Red TR salt (Sigma Chemical Co., St. Louis, MO) after further washing in Tris buffer. Immunostaining for Tamm-Horsfall protein (THP) was performed with an anti-THP sheep serum and alkaline phosphataseconjugated donkey anti-sheep second antibody (Chemicon International Inc., Temecula, CA). The slides were deparaffinized and heat treated as described previously in this article. Isotype-matched mouse $\mathrm{IgG}$, normal rabbit serum, or normal sheep serum was used as a negative control for the immunostainings.

Quantitative evaluation of HO-1 mRNA and HO-1 protein levels. Levels of HO-1 protein and HO-1 mRNA expression within glomeruli, proximal tubuli, and distal tubuli were evaluated separately. Proximal tubuli were differentiated from distal tubuli on the basis of the following criteria. Proximal tubuli had larger diameters than distal tubuli. The nuclei of proximal tubular epithelial cells were generally arrayed at the base of the cells. Most proximal tubular epithelial cells had obvious brush borders. In some cases with severe tubulointerstitial damage, THP staining was used as a specific marker for distal tubuli. Two consecutive specimens for HO-1 and THP stainings were compared with differentiate proximal tubuli from distal tubuli. The intensity and the distribution of HO-1 mRNA expression within proximal and distal tubuli were evaluated as follows. The degree of HO-1 mRNA expression within tubuli was classified into point 0 to point 3 as follows: point 0 , no staining; point 1 , weak and focal; point 2 , weak and diffuse or strong and focal; point 3 , strong and diffuse (Fig. 1). Within glomeruli, the degrees of HO-1 mRNA expression were evaluated by the patterns of its distribution. The levels were classified into point 0 to point 3 as follows: point 0 , no staining; point 1 , focal 


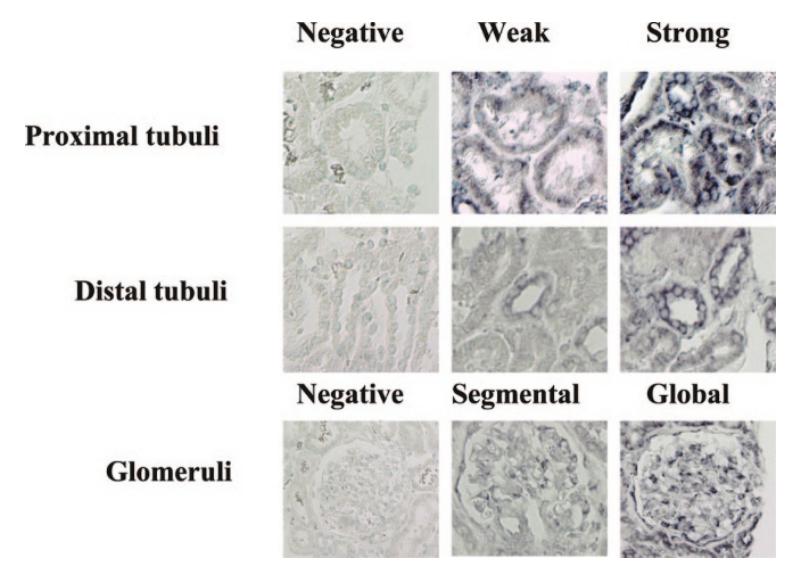

Figure 1. Evaluation of the levels of HO-1 mRNA expression. Intensity of HO-1 mRNA staining within glomeruli, proximal tubuli, and distal tubuli was evaluated by in situ hybridization. Representative figures within proximal and distal tubuli for negative, weak, and strong staining are shown. Representative figures within glomeruli for negative, segmental, and global are shown. Negative controls are the kidney specimens from the HO-1-deficient case. Magnification: $\times 400$.

and segmental; point 2, diffuse and segmental or focal and global; point 3, diffuse and global (Fig. 1). As previously reported for immunohistochemical staining, the degree of HO-1 protein staining was classified into point 0 to point 4 as follows: point 0 , no staining; point 1 , weak and focal; point 2 , weak and diffuse or moderate and focal; point 3 , moderate and diffuse or strong and focal; point 4, strong and diffuse (12). Five nephrologists examined the specimens independently and judged the staining patterns without knowledge of the patient's histologic diagnosis. Mean points \pm SD were calculated.

Statistics. Data are expressed as mean \pm SD. For comparison of two groups, the Mann-Whitney test was used as appropriate. For the correlation between the intensity of HO-1 mRNA staining and HO-1 protein immunostaining, Spearman's correlation coefficient by rank was used as appropriate. Values are considered statistically significant at $p<0.05$.

\section{RESULTS}

Expression patterns of $\mathrm{HO}-1$ protein in various renal diseases. HO-1 protein expression in various renal diseases was examined in more cases than our previous report (12). It is shown in the following that the patterns of HO-1 protein expression were same as the results in our previous report. In short, HO-1 protein was observed within tubular epithelial cells in all of the renal diseases but not within intrinsic glomerular cells, including mesangial cells, glomerular endothelial cells, and glomerular epithelial cells. HO-1 expression tended to be more intense within distal tubuli than in proximal tubuli. Within distal tubuli, there was no significant correlation between the level of HO-1 protein and the degree of hematuria or presence of proteinuria. Within proximal tubuli, HO-1 staining tended to be more intense with greater degrees of hematuria, presence of proteinuria, and moderate tubulointerstitial damage (data not shown).

Spatial localization of renal HO-1 mRNA production. HO-1 mRNA was not detectable in any part of the kidney specimen from the HO-1-deficient patient (Fig. 1). In marked contrast, expression of HO-1 mRNA was recognized within renal proximal and distal tubular epithelial cells (Fig. 1) and infiltrating macrophages (Fig. 2). HO-1 mRNA expression tended to be more intense within distal tubuli $(1.76 \pm 0.73$ points) than proximal tubuli (1.02 \pm 0.58 points) in all of the specimens (Mann-Whitney test, $p<0.001$ ). It was intriguing

\section{A : HO-1 mRNA}
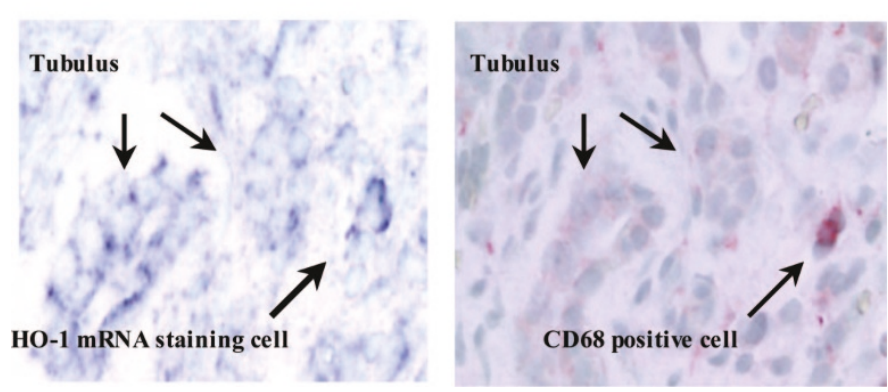

Figure 2. HO-1 mRNA expression within interstitium and CD68-positive macrophages. HO-1 mRNA expression was detected within the interstitium (A). Immunohistochemical examination of consecutive renal sections indicated that the cells expressing HO-1 mRNA within the interstitium were CD68positive macrophages $(B)$. Magnification: $\times 400$.

that HO-1 mRNA was detectable also within glomerular epithelial cells and Bowman's epithelial cells, which did not express HO-1 protein (Fig. $3 A$ and $B$ ). HO-1 mRNA and protein were not detected within mesangial cells or glomerular endothelial cells. No signal was detected with sense RNA probe (Fig. 3C). HO-1 mRNA was weakly but consistently detectable within both proximal and distal tubular epithelial cells in patients with MCNS without proteinuria, who served as normal control subjects.

Correlation between HO-1 mRNA and HO-1 protein. Figure 4 shows the correlation between the intensity of HO-1 mRNA expression and HO-1 protein immunostaining. There was a weak correlation between the intensity of HO-1 mRNA staining and HO-1 protein immunostaining within proximal tubuli $(\mathrm{R}=0.31, \mathrm{Y}=1.411+0.375 \mathrm{X}$, Spearman's correlation coefficient by rank, $p<0.05$; Fig. $4 A$ ). Furthermore, HO- 1 protein immunostaining tended to be more intense as compared with HO-1 mRNA expression within proximal tubuli (Fig. 4C and E). Both HO-1 mRNA expression and HO-1 protein immunostaining tended to be more intense in distal tubuli than in proximal tubuli (Fig. $4 B, D$, and $F$ ), and there was no correlation between the levels of HO-1 mRNA and HO-1 protein within distal tubuli. The levels of HO-1 protein remained constant, regardless of the degree of HO-1 mRNA expression (Fig. 4B).

HO-1 mRNA expression in various renal diseases. Figure 5 shows the intensity of HO-1 mRNA staining in various renal diseases. Within proximal tubuli, the level of HO-1 mRNA expression did not differ significantly among various renal diseases. Within glomeruli, the intensity of HO-1 mRNA expression was stronger in Mes-PGN than in MCNS, but there was no disease-specific pattern of HO-1 mRNA expression for any of these illnesses. A noteworthy finding was that HO-1 mRNA expression was significantly more intense in five patients with MCNS and proteinuria as compared with four patients without proteinuria within all areas (Fig. 5).

Correlation between the level of HO-1 mRNA expression and the degrees of proteinuria or hematuria and other clinical characteristics. In Mes-PGN, HO-1 mRNA expression correlated with the degree of proteinuria within all segments of the renal tissue (Mann-Whitney test, ${ }^{*} p<0.05,{ }^{*} p<0.01$; 

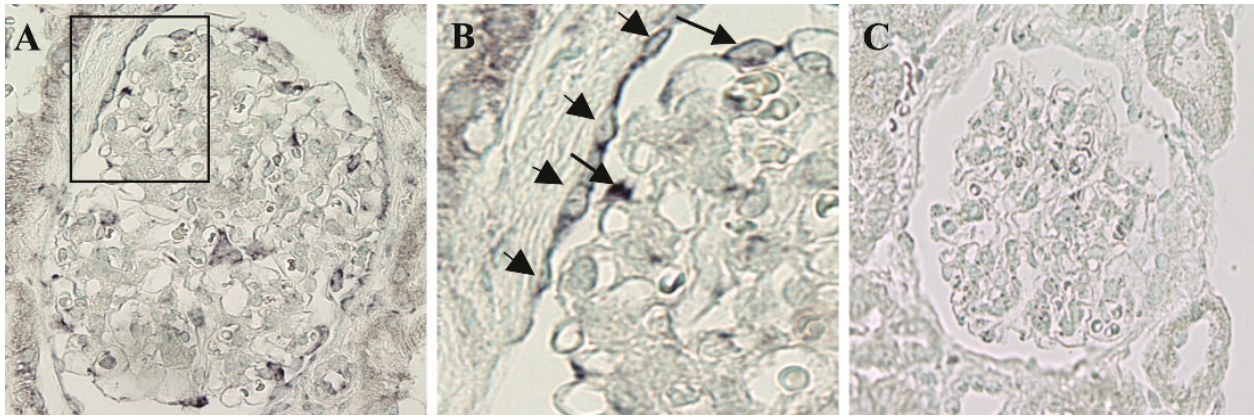

Figure 3. Demonstration of HO-1 mRNA expression within glomeruli. HO-1 mRNA expression was detected within glomeruli $(A)$. A high-power view shows that the cells expressing HO-1 mRNA within glomeruli are the glomerular epithelial cell (arrows) located outside the capillary wall and Bowman's epithelial cells (arrowheads; $B$ ). No signal was detected with sense RNA probe $(C)$. Magnification: $\times 400$ in $A$ and $C ; \times 1000$ in $B$.

A
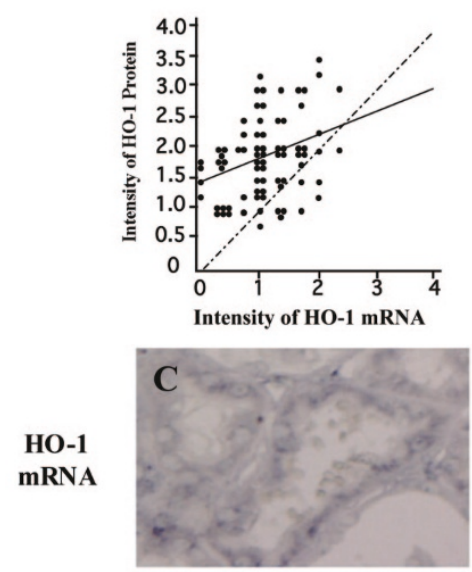

HO-1

Protein

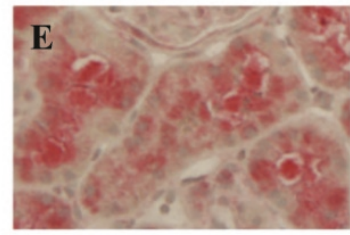

Proximal tubuli
B
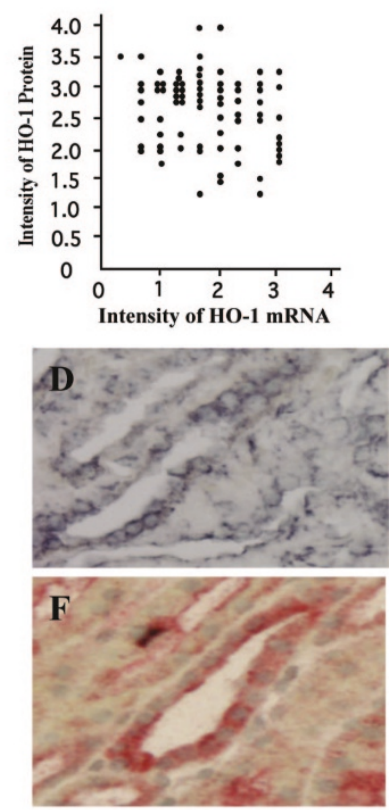

Distal tubuli

Figure 4. Correlation between the intensity of HO-1 mRNA expression and HO-1 immunostaining. There was a weak correlation between the intensity of HO-1 mRNA expression and HO-1 immunostaining within proximal tubuli $(\mathrm{R}=0.31, \mathrm{Y}=1.411+0.375 \mathrm{X}$, Spearman's correlation coefficient by rank, $p<0.05 ; A)$, but the intensity of HO-1 immunostaining tended to be more intense as compared with the intensity of HO-1 mRNA expression within proximal tubuli ( $C$ : HO-1 mRNA staining; $E$ : HO-1 immunostaining). In contrast, there was no correlation between the intensities of HO-1 mRNA and HO-1 protein within distal tubuli $(B)$. Within distal tubuli, both the intensity of HO-1 mRNA expression and HO-1 immunostaining tended to be more intense than proximal tubuli ( $D$ : HO-1 mRNA staining; $F$ : HO-1 immunostaining).

Fig. 6). Although HO-1 protein expression correlated well with the degree of hematuria, the levels of HO-1 mRNA did not. Age, gender, blood pressure, serum creatinine level, urinary NAG levels, and urinary $\beta_{2}$-mg levels of these patients did not seem to affect HO-1 expression in any of the illnesses (data not shown).

\section{DISCUSSION}

HO-1 is an inducible enzyme, and its optimal (appropriate levels at the best time, at the best location) induction is critical

to protect tissue from oxidative stress and to reduce tissue damage during inflammation. In this particular study, we examined HO-1 mRNA expression in vivo in various renal diseases by in situ hybridization and compared it with HO-1 protein expression as related to various clinical features.

To our surprise, HO-1 mRNA expression in human kidney was observed not only within tubular epithelial cells and infiltrating macrophages but also at the same time within glomerular epithelial cells and Bowman's epithelial cells. It was expected that glomerular epithelial cells express significant levels of HO-1 mRNA, considering that they are the component of the glomerular filtration system that is constantly exposed to various forms of oxidative stress. Two mechanisms of HO-1 mRNA expression within glomerular epithelial cells are considered. One mechanism may be that proteinuria through glomerular basement membrane may induce HO-1 expression. The other may be that HO-1 within glomerular epithelial cells is induced by other factors, such as glomerular permeability factor, and the proteinuria occurs as the result.

However, it is not clear why HO-1 mRNA was expressed within renal glomerular epithelial cells, despite that HO-1 protein was not detectable. This discrepancy can be explained by the differences in the sensitivity and the specificity between the immunohistochemical method and in situ hybridization. It may be that our immunohistochemical method is not sensitive enough to detect low levels of expression by intrinsic glomerular cells. Another possibility, although less likely, is that HO- 1 protein is secreted into the tubular lumen as soon as it is produced within glomerular epithelial cells. It may exert a function within glomerular epithelial cells totally distinct from its role within tubular epithelial cells. Proximal tubular epithelium is known to express two molecules, megalin and tubulin, which together serve as receptors for various filtered proteins, including albumin (26). Tubular reabsorption of HO-1 protein through these receptors may explain the finding that there was an unexpectedly high level of HO-1 protein within proximal tubuli, where HO-1 mRNA was expressed only at modest levels. These results also support the view that HO-1 protein secreted from glomerular epithelial cell is reabsorbed by proximal tubular cells. However, we do not have other evidence to support the latter hypothesis at this moment, and further studies are necessary to draw any conclusion. 


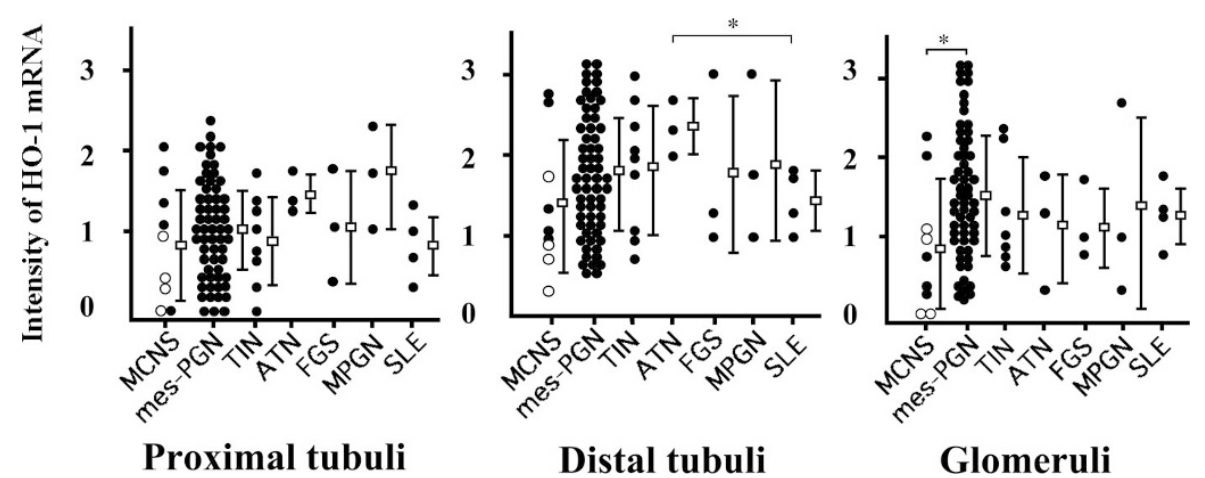

Figure 5. Quantitative analysis of HO-1 mRNA expression in various renal diseases. The intensity of HO-1 mRNA expression was stronger in acute tubular necrosis (ATN) as compared with systemic lupus erythematosus (SLE) within distal tubuli, and the intensity of HO-1 mRNA expression was stronger in Mes-PGN as compared with MCNS within glomeruli. O, MCNS without proteinuria at the time of renal biopsy.

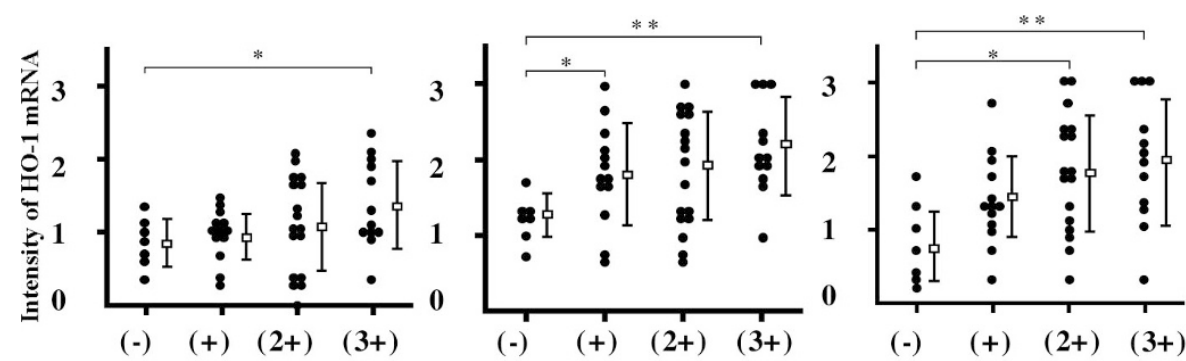

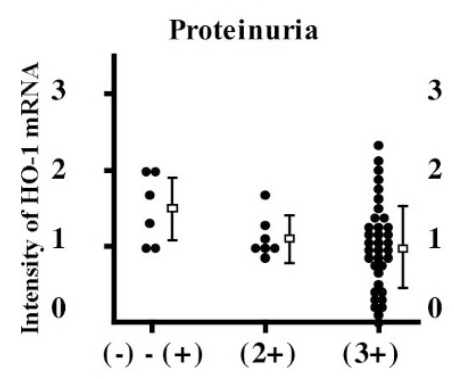

Hematuria

Proteinuria

Proteinuria

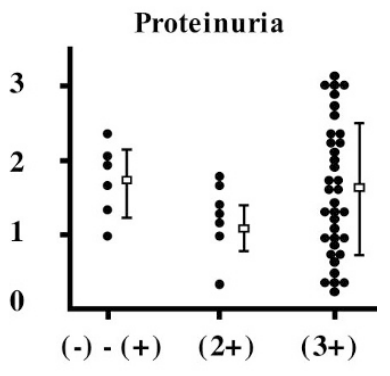

Hematuria

Proximal tubuli

Distal tubuli

\section{Glomeruli}

Figure 6. Correlation between HO-1 mRNA expression and the degrees of proteinuria or hematuria. In Mes-PGN, the intensity of HO-1 mRNA expression tended to be greater with greater degrees of proteinuria (Mann-Whitney test, $* p<0.05, * * p<0.01$ ). There was no correlation between the intensity of HO-1 mRNA expression and the degree of hematuria.

Within distal tubuli, HO-1 mRNA expression was consistently more intense than in proximal tubuli, similar to HO-1 protein expression. This is in agreement with the previous reports indicating that $\mathrm{HO}$ and its products play an important role in maintaining the constancy of blood flow to the renal medulla (27).

In the present study, our results did not show any direct correlations between clinical diagnosis and expression of HO-1 gene within the kidney. Thus, the data do not provide a basis to make a specific pathologic or etiologic diagnosis on the basis of the patterns or the levels of HO-1 mRNA expression, and we cannot use them as tools to choose the suitable therapeutic options or estimate the prognosis of the kidney pathology.

Nevertheless, the amount of urinary protein correlated significantly with the level of HO-1 mRNA expression. HO-1 mRNA expression tended to be more intense with greater degree of proteinuria in patients with Mes-PGN. Similarly, the intensity of HO-1 mRNA was stronger in patients MCNS and proteinuria than in those without proteinuria. Urinary proteins are themselves cytotoxic, and reabsorption of urinary proteins induces reactive oxygen species production within tubular epithelial cells. A recent study reported that albumin that represents glomerular proteinuria stimulates tubular IL-8 expression, which is dependent on the endocytosis of albumin that triggers a cascade of intracellular signals from protein kinase $\mathrm{C}$-dependent activation of reactive oxygen species generation (28). HO-1 may protect glomerular and tubular epithelial cells from oxidative stress induced by glomerular proteinuria.

Tubulointerstitial injury can impair renal function through multiple pathways. It is a pathologic process that is consistently present in various kidney diseases. It has been reported that renal functional impairment correlates more closely with tubulointerstitial changes than with glomerular injury in all 
renal diseases (29). The severity of tubulointerstitial injury correlates with the level of proteinuria (30). In the first reported human HO-1 deficiency case, progressive tubulointerstitial damage was the principal feature of the renal damage (31). In this study, HO-1 mRNA expression tended to be more intense with greater degrees of glomerular proteinuria within renal tubular epithelial cells. From these observations, we speculated that HO-1 is essential to protect renal tubular epithelial cells from oxidative injury and prevent progression to renal failure. However, there was little direct correlation between the intensity of HO-1 mRNA expression and the degree of hematuria within all areas. These conflicting results may indicate that hematuria is a much weaker stress in inducing HO-1 production than proteinuria. Although it is well known that heme protein derived from broken erythrocytes induces HO-1 expression, intact erythrocytes may not do so.

\section{CONCLUSIONS}

These results show that HO-1 plays pivotal roles in the maintenance of renal functions and protection of renal structures under oxidative stress (e.g. glomerular proteinuria), especially within renal glomerular and tubular epithelial cells. The mechanism of oxidative injury in the kidney will be the focus of future studies, which will further clarify the protective roles of HO-1 in the pathogenesis of various renal diseases.

Acknowledgments. We thank Akiko Katayama for technical assistance.

\section{REFERENCES}

1. Maines MD 1984 New developments in the regulation of heme metabolism and their implication. CRC Crit Rev Toxicol 12:241-314

2. Maines MD 1998 Heme oxygenase-1: function, multiplicity, regulatory mechanisms, and clinical applications. FASEB J 2:2557-2568

3. Choi AM, Alam J 1996 Heme oxygenase-1: function, regulation, and implication of a novel stress-inducible protein in oxidant-induced lung injury. Am J Respir Cell Mol Biol 15:9-19

4. Stocker R, Yamamoto Y, McDonagh AF, Glazer AN, Ames BN 1987 Bilirubin is an antioxidant of possible physiological importance. Science 235:1043-1046

5. Nakagami T, Toyomura K, Kinoshita T, Morisawa S 1993 A beneficial role of bile pigments as an endogenous tissue protector: anti-complement effects of biliverdin and conjugated bilirubin. Biochim Biophys Acta 1158:189-193

6. Ingi T, Cheng J, Ronnett GV 1996 Carbon monoxide: an endogenous modulator of the nitric oxide-cyclic GMP signaling system. Neuron 16:835-842

7. Seki T, Naruse M, Naruse K, Yoshimoto T, Tanabe A, Tsuchiya K, Hirose S, Imaki T, Nihei H, Demura H 1998 Roles of heme oxygenase/carbon monoxide system in genetically hypertensive rats. Biochem Biophys Res Commun 241:574-578

8. Juckett MB, Balla J, Balla G, Jessurun J, Jacob HS, Vercellotti GM 1995 Ferritin protects endothelial cells from oxidized low density lipoprotein in vitro. Am J Pathol 147:782-789
9. Balla G, Jacob HS, Balla J, Rosenberg M, Nath K, Apple F, Eaton JW, Vercellotti GM 1992 Ferritin: a cytoprotective antioxidant stratagem of endothelium. J Biol Chem 267:18148-18153

10. Berglund L, Galbraith RA, Emtestam L, Drummond GS, Angelin B, Kappas A 1999 Heme oxygenase inhibitors transiently increase serum ferritin concentrations without altering other acute-phase reactants in man. Pharmacology 59:51-56

11. McCoubrey WK Jr, Huang TJ, Maines MD 1997 Isolation and characterization of a cDNA from the rat brain that encodes hemoprotein heme oxygenase-3. Eur J Biochem 247:725-732

12. Morimoto K, Ohta K, Yachie A, Yang Y, Shimizu M, Goto C, Toma T, Kasahara Y, Yokoyama H, Miyata T, Seki H, Koizumi S 2001 Cytoprotective role of heme oxygenase (HO)-1 in human kidney with various renal diseases. Kidney Int 60:18581866

13. Nath KA, Balla G, Vercellotti GM, Balla J, Jacob HS, Levitt MD, Rosenberg ME 1992 Induction of heme oxygenase is a rapid, protective response in rhabdomyolysis in the rat. J Clin Invest 90:267-270

14. Mosley K, Wembridge DE, Cattell V, Cook HT 1998 Heme oxygenase is induced in nephrotoxic nephritis and hemin, a stimulator of heme oxygenase synthesis, ameliorates disease. Kidney Int 53:672-678

15. Ishizuka S, Nagashima Y, Nimata M, Yano T, Hagiwara K, Ozasa H, Sone M, Nihei H, Horikawa S 1997 Regulation and immunohistochemical analysis of stress protein heme oxygenase-1 in rat kidney with myoglobinuric acute renal failure. Biochem Biophys Res Commun 240:93-98

16. Vogt BA, Alam J, Croatt AJ, Vercellotti GM, Nath KA 1995 Acquired resistance to acute oxidative stress. Possible role of heme oxygenase and ferritin. Lab Invest $72: 474-483$

17. Agarwal A, Balla J, Alam J, Croatt AJ, Nath KA 1995 Induction of heme oxygenase in toxic renal injury: a protective role in cisplatin nephrotoxicity in the rat. Kidney Int 48:1298-1307

18. Nath KA, Croatt AJ, Likely S, Behrens TW, Warden D 1996 Renal oxidant injury and oxidant response induced by mercury. Kidney Int 50:1032-1043

19. Vogt BA, Shanley TP, Croatt AJ, Alam J, Johnson KJ, Nath KA 1996 Glomerular inflammation induces resistance to tubular injury in the rat. A novel form of acquired, heme oxygenase-dependent resistance to renal injury. J Clin Invest 98:2139-2145

20. Horikawa S, Ito K, Ikeda S, Shibata T, Ishizuka S, Yano T, Hagiwara K, Ozasa H, Katsuyama I 1998 Induction of heme oxygenase-1 in toxic renal injury: mercuric chloride-induced acute renal failure in rat. Toxicol Lett 94:57-64

21. Tetsuka T, Daphna-Iken D, Srivastava SK, Morrison AR 1995 Regulation of heme oxygenase mRNA in mesangial cells: prostaglandin E2 negatively modulates interleukin-1-induced heme oxygenase-1 mRNA. Biochem Biophys Res Commun 212:617-623

22. Datta PK, Lianos EA 1999 Nitric oxide induces heme oxygenase-1 gene expression in mesangial cells. Kidney Int 55:1734-1739

23. Berger SP, Hunger M, Yard BA, Schnuelle P, Van Der Woude FJ 2000 Dopamine induces the expression of heme oxygenase-1 by human endothelial cells in vitro. Kidney Int 58:2314-2319

24. Bek MJ, Wahle S, Muller B, Benzing T, Huber TB, Kretzler M, Cohen C, BusseGrawitz A, Pavenstadt H 2003 Stra13, a prostaglandin E2-induced gene, regulates the cellular redox state of podocytes. FASEB J 17:682-684

25. Yang Y, Ohta K, Shimizu M, Morimoto K, Goto C, Nakai A, Toma T, Kasahara Y, Yachie A, Seki H, Koizumi S 2003 Selective protection of renal tubular epithelial cells by heme oxygenase (HO)-1 during stress-induced injury. Kidney Int 64:1302 1309

26. Christensen EI, Birn H 2001 Megalin and cubilin: synergistic endocytic receptors in renal proximal tubule. Am J Physiol 280:F562-F573

27. Zou AP, Billington H, Su N, Cowley AW Jr 2000 Expression and actions of heme oxygenase in the renal medulla of rats. Hypertension 35:342-347

28. Tang S, Leung JC, Abe K, Chan KW, Chan LY, Chan TM, Lai KN 2003 Albumin stimulates interleukin-8 expression in proximal tubular epithelial cells in vitro and in vivo. J Clin Invest 111:515-527

29. Nath KA 1992 Tubulointerstitial changes as a major determinant in the progression of renal damage. Am J Kidney Dis 20:1-17

30. Benigni A, Zoja C, Remuzzi G 1995 The renal toxicity of sustained glomerular protein traffic. Lab Invest 73:461-468

31. Ohta K, Yachie A, Fujimoto K, Kaneda H, Wada T, Toma T, Seno A, Kasahara Y, Yokoyama H, Seki H, Koizumi S 2000 Tubular injury as a cardinal pathologic feature in human heme oxygenase-1 deficiency. Am J Kidney Dis 35:868-870 